\section{Use of Feldspathic Porcelain Veneers to Improve Smile Harmony: A 3-Year Follow-up Report}

Leonardo Federizzi ${ }^{1,3}$, Érica Alves Gomes ${ }^{1}$, Samantha Schaffer Pugilato

Báratro ${ }^{2}$, Flares Baratto-Filho ${ }^{2}$, Ataís Bacchi ${ }^{3}$, Aloísio Oro Spazzin ${ }^{3}$

\author{
'School of Dentistry, UNAERP \\ - University of Ribeirão Preto, \\ Ribeirão Preto, SP, Brazil \\ ${ }^{2}$ Department of Dentistry, \\ UP - Universidade Positivo, \\ Curitiba, PR, Brazil \\ ${ }^{3}$ School of Dentistry, IMED \\ - Meridional University, \\ Passo Fundo, RS, Brazil
}

Correspondence: Prof. Aloísio

Spazzin, Rua Senador Pinheiro 304, 99070-220 Passo Fundo, RS, Brasil. Tel: +55-54-3045-6100.

e-mail: aospazzin@yahoo.com.br

Key Words: feldspathic porcelain veneers, smile harmony, esthetic treatment.

\section{Introduction}

Decision making for the treatment of esthetic areas is performed with the aim of providing a healthy, harmonious and beautiful smile. The ability to achieve this goal is associated directly with a solid knowledge of tooth anatomy and proportions, as well as of the smile line, soft-tissue morphology and osseous architecture (1). Most restorative materials available for esthetic treatment are composite resins and ceramics, each of which has advantages and limitations (2). Composite resin can be used to mask tooth discoloration and/or to correct unaesthetic tooth shape and/or position. However, such restorations have limited longevity, which compromises the long-term esthetic results $(3,4)$. Ceramic laminate veneers are also used commonly for esthetic treatments, involving morphological modifications related to tooth color, shape, contour, size and volume, and to correct dental alignment $(5,6)$. Current adhesive procedures enable the performance of minimally invasive treatment that preserves the tooth structure, satisfying restorative needs and patients' esthetic requirements. Several ceramic materials and fabrication methods for laminate veneers are available; materials include feldspathic porcelain and glass-based ceramics (7).

Feldspathic porcelain is intrinsically friable and fragile, but it may be strengthened by luting to the dental structure using a resin-based agent (8-11). Feldspathic porcelain made on a refractory cast can restore tooth shape and color effectively, with control over other restoration parameters, such as marginal accuracy, emergence profile and incisal translucency (12). This type of porcelain is particularly useful for esthetic veneers because of the absence of a core material, which allows for more conservative tooth preparation, a thinner and more natural emergence profile in the cervical region, and increased space for characterization in the middle and incisal thirds (13). Thin feldspathic porcelain veneers have high clinical survival rates when some important parameters are observed (14), which are discussed in this clinical report. The purpose of this report is to present a case of esthetic treatment to improve anterior tooth shape and alignment, thereby reestablishing the esthetics and harmony of the patient's smile, using feldspathic porcelain veneers. Outcomes after 3 years of clinical follow up are described.

\section{Case Report}

A 52-year-old female patient was referred to a private clinic due to her dissatisfaction with the esthetics of her smile, particularly the chromatic difference and lack of harmony in the positioning of the maxillary anterior teeth. Clinical examination revealed changes in the shape, position, color and in some cases, presence of resin composite restorations on the proximal surfaces of the maxillary anterior teeth (Figs. 1 and 2). After comprehensive evaluation and collection of data regarding the patient's complaint, a treatment plan including the application of feldspathic porcelain veneers to the maxillary anterior teeth and first premolars was developed.

A maxillary impression was taken with polyvinylsiloxane impression material (Express XT; 3M ESPE, St. Paul, MN, USA) 
and a mandibular impression was taken with irreversible hydrocolloid impression material (Hydrogum 5; Zhermack, Badia Polesine, RO, Italy). The impressions were poured with type IV dental stone (Fujirock; GC Corp., Tokyo, Japan), according to the manufacturer's instructions. Casts were articulated in maximum intercuspation on a semi-adjustable articulator (A7 Fix; BioArt, São Carlos, $\mathrm{SP}$, Brazil) with a face-bow transfer (Elite; BioArt) (Fig. 3A). The laboratory completed a diagnostic wax-up for presentation of the proposed shape and contour of the final laminate porcelain veneers to the patient (Fig. 3B). A diagnostic mock-up was made using bis-acryl composite resin (Protemp 4;3M ESPE) to evaluate the final shape of the teeth, the new smile architecture and facial harmony (Fig. 3C). This procedure enables tridimensional pre-visualization of the final result prior to the preparation procedure (15).

After the patient expressed agreement with the final shape of the teeth on the wax-up, the teeth were prepared using diamond burs (\#3216, \#3215, \#3215F, \#3216F; KG Sorensen, Barueri, SP, Brazil) and dental tissue reduction was performed using silicon guides (Zetaplus; Zhermack) obtained from a diagnostic waxed cast (Fig. 4A). The preparation was finished using multilayered carbide burs
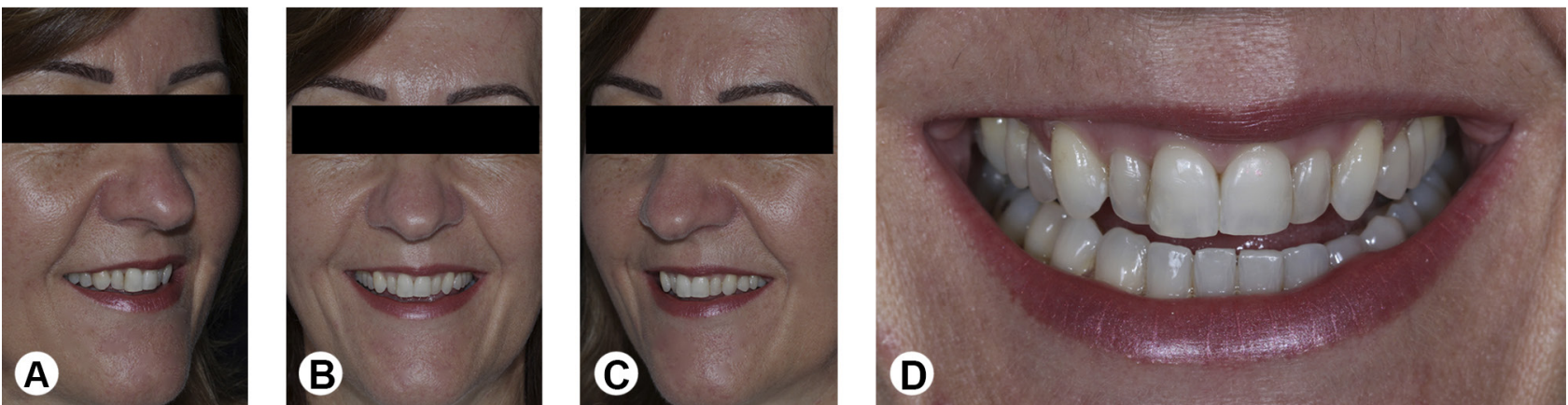

Figure 1. Pretreatment facial (A-C) and close-up smile (D) views.
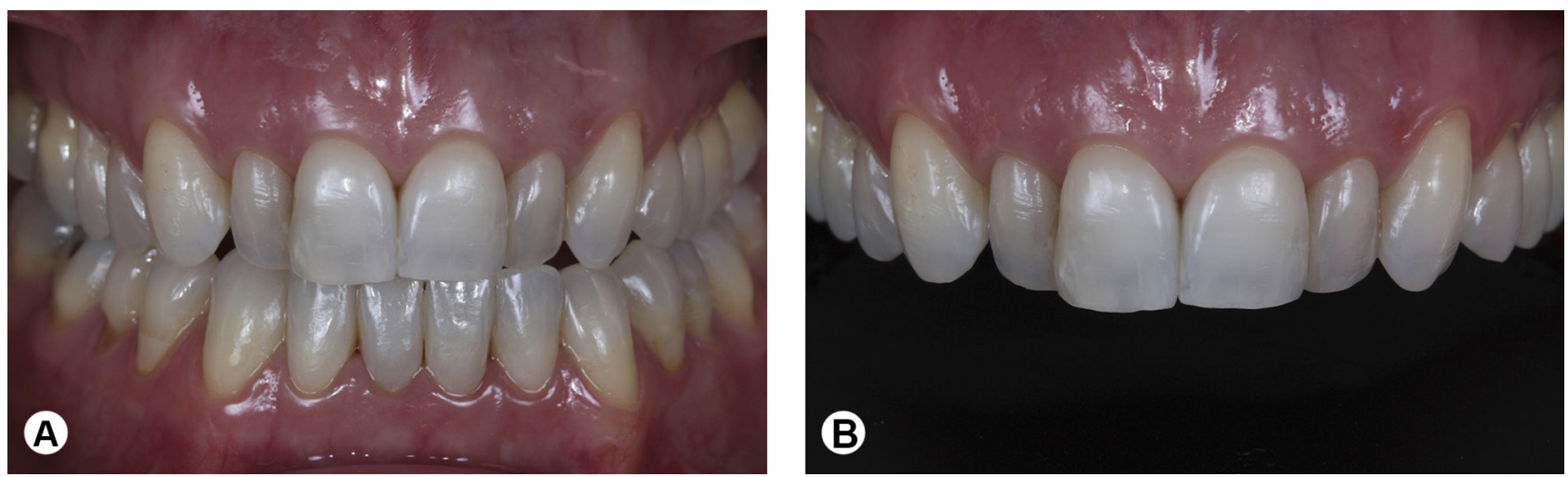

Figure 2. Pretreatment intraoral views of (A) maximum intercuspation and (B) maxillary anterior teeth. 
charged with fluid material; while simultaneously removing the second cord, the fluid material was inserted into the gingival sulcus until it filled all preparations and occlusal faces of the adjacent teeth. The impression was washed in running water and air dried, and the correct reproduction of the structures was verified (Fig. 4F).

A photographic protocol was followed for shade matching using a VITA classical shade guide (Figs. 5A and B). Provisional restorations were made using bis-acryl composite resin (Protemp 4; 3M ESPE) with a silicone mold (Express XT; 3M ESPE) that had been made previously on the cast from the diagnostic wax-up (Fig. 5C). Special care was given to remove excess material from the cervical margins to avoid inflammation of the gingival tissue (Fig. 5D-F). The impression with the preparations was poured with type IV dental stone (Fujirock; GC Corp.; Figure 6A). The prepared, mandibular and diagnostic wax-up casts were sent to the dental laboratory (Calgaro, Curitiba, PR, Brazil) for the creation of refractory dies and fabrication of feldspathic porcelain veneers (IPS d.Sign; Ivoclar Vivadent,
Schaan, Liechtenstein) (Fig. 6B-E).

In a clinical session one month later, the shape and marginal adaptation of the laminate veneers were evaluated on the prepared cast (Fig. 7). The provisional restorations were removed and the preparations were cleaned and the marginal adaptation of the laminate veneers was evaluated individually on the preparations. Posteriorly, the shape, shade and esthetic harmony of all laminate veneers were evaluated together. The internal surfaces of the porcelain restorations were etched with 4.5\% hydrofluoric acid (IPS Ceramic Etching Gel; Ivoclar Vivadent) for $90 \mathrm{~s}$, then washed under running water and air dried. They were then cleaned with 37\% phosphoric acid (Condac 37; FGM, Joinvile, SC, Brazil) for $60 \mathrm{~s}$, washed under running water and air dried. A silane coupling agent (Monobond; Ivoclar Vivadent) was applied for $60 \mathrm{~s}$, according to the manufacturer's instructions. For the dental substrate treatment, 37\% phosphoric acid (Condac 37; FGM) was applied for $15 \mathrm{~s}$, followed by washing and air drying; two consecutive coats of the adhesive system (Single bond 2; 3M ESPE) were then

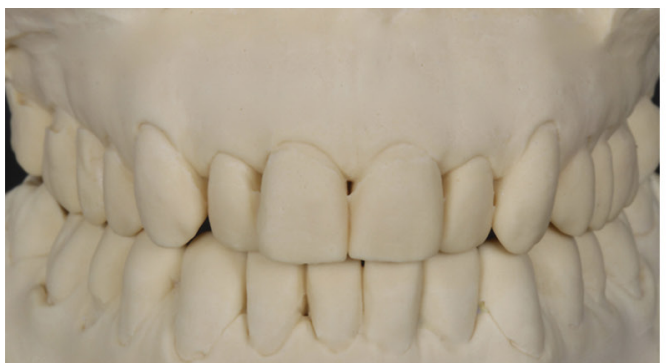

A

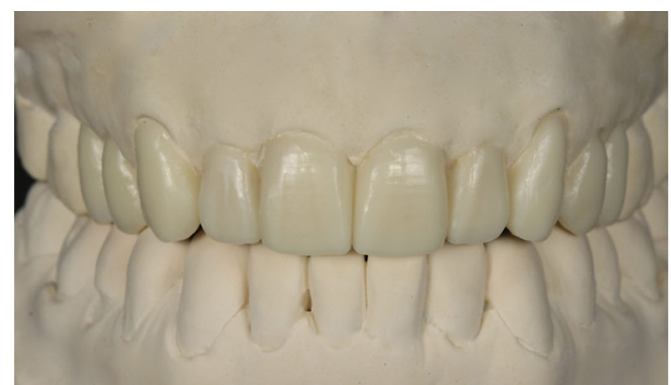

B

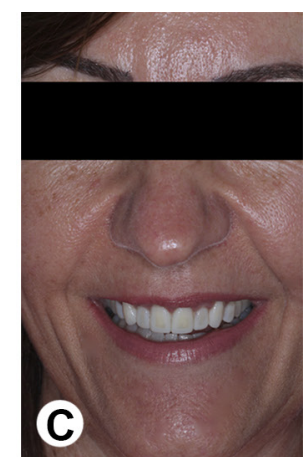

C

Figure 3. Casts articulated in maximum intercuspation (A), diagnostic wax-up (B), and facial view with diagnostic mock-up using bis-acryl composite resin (C).
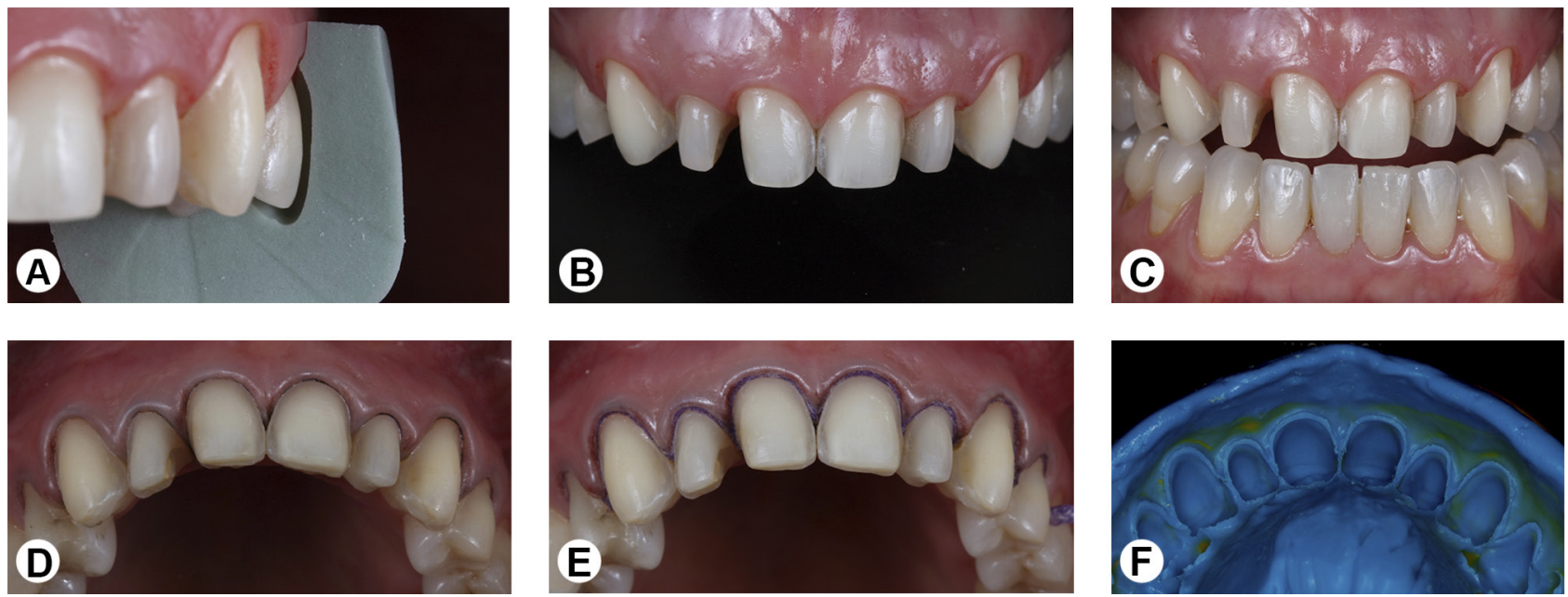

Figure 4. Teeth were prepared using silicon guides (A). Teeth after preparation for laminate veneers (B, C), placement of retraction cords for impression (D, E) and impression of the preparations (F). 
applied for $15 \mathrm{~s}$ each with gentle agitation, then gently air dried for $5 \mathrm{~s}$ to evaporate solvents and light cured for 10 s using a LED unit with $1200 \mathrm{~mW} / \mathrm{cm}^{2}$ irradiance (Radii; SDI, Bayswater, Victoria, Australia). A thin layer of adhesive
(Bond, Adper Scotchbond Multipurpose Plus; 3M ESPE) was applied to the insides of the restorations prior to the luting agent and not cured. The laminate veneers were luted using a light-cured luting agent (base paste Transparent Variolink
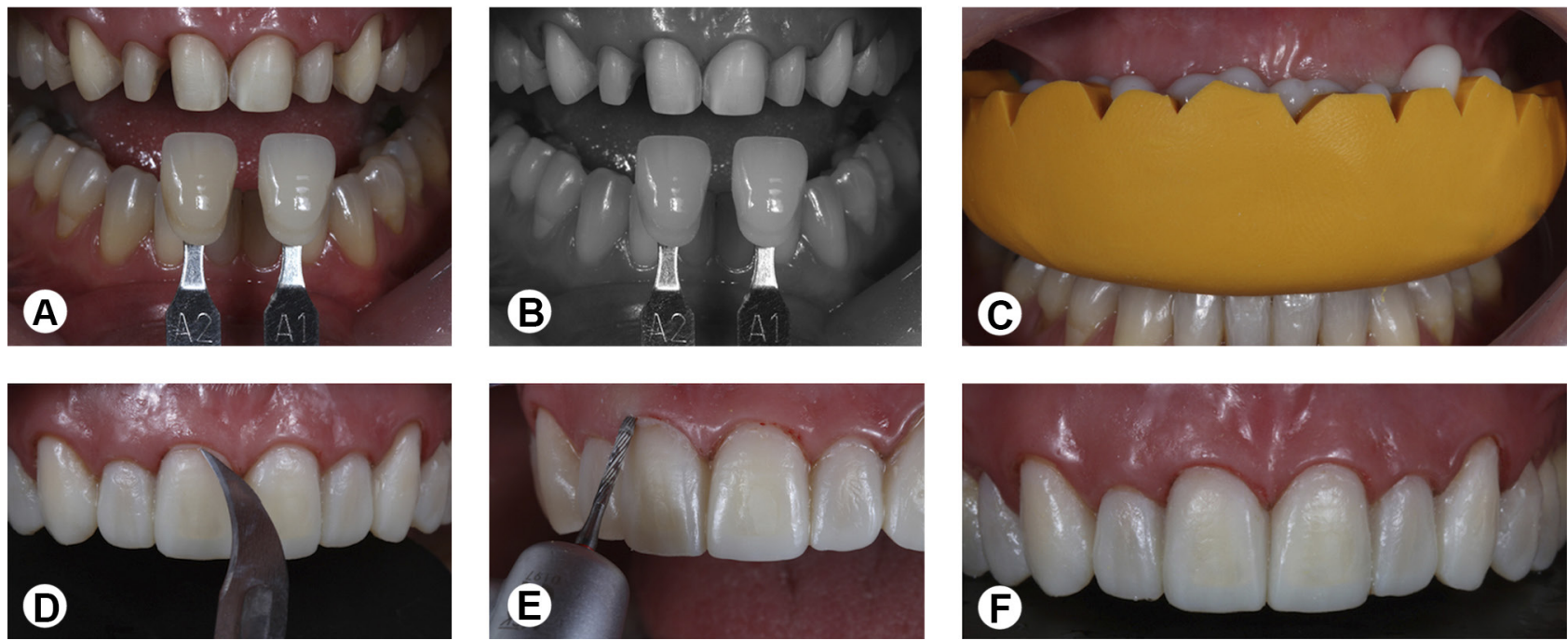

Figure 5. Photographic evaluation for shade matching (A, B). Provisional restorations made using bis-acryl composite resin with a silicone mold (C-F).
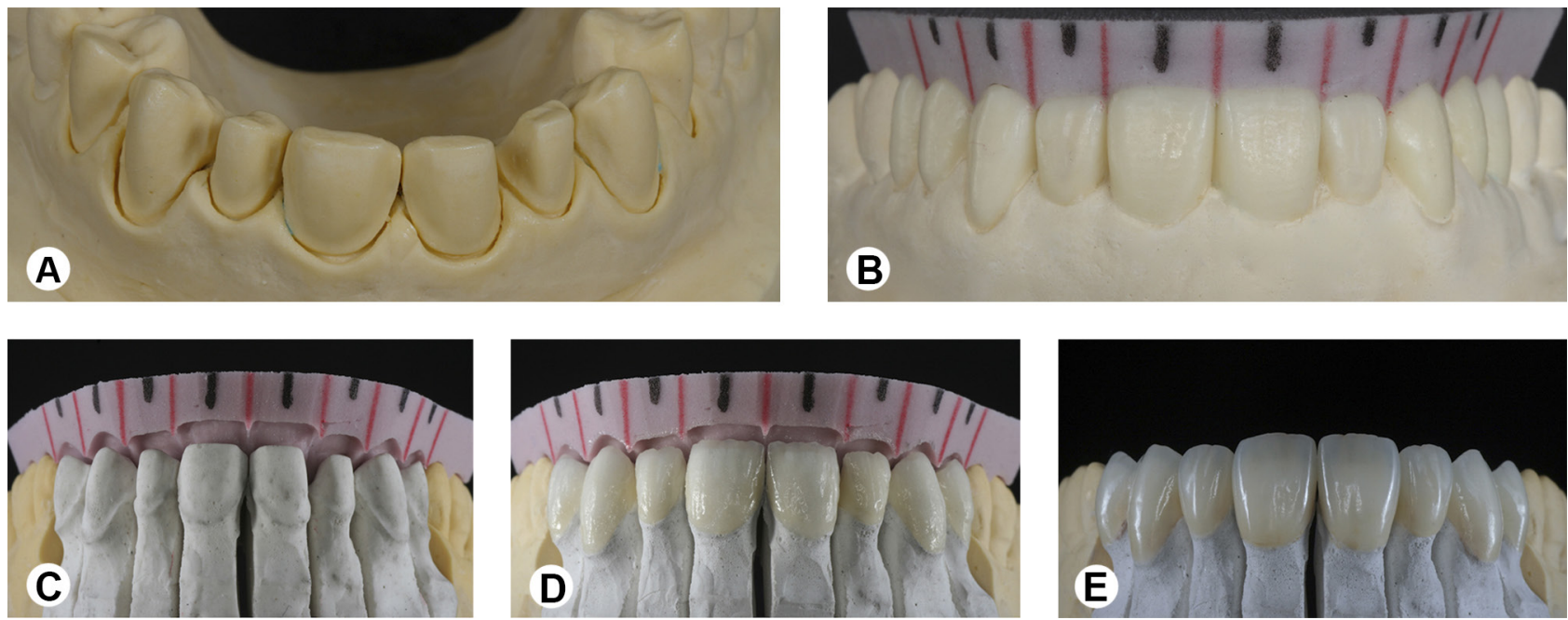

Figure 6. Cast with the preparations (A), silicon guides from diagnostic wax-up to orient the fabrication of the restorations (B), and feldspathic porcelain veneers made on the refractory dies (C-E).
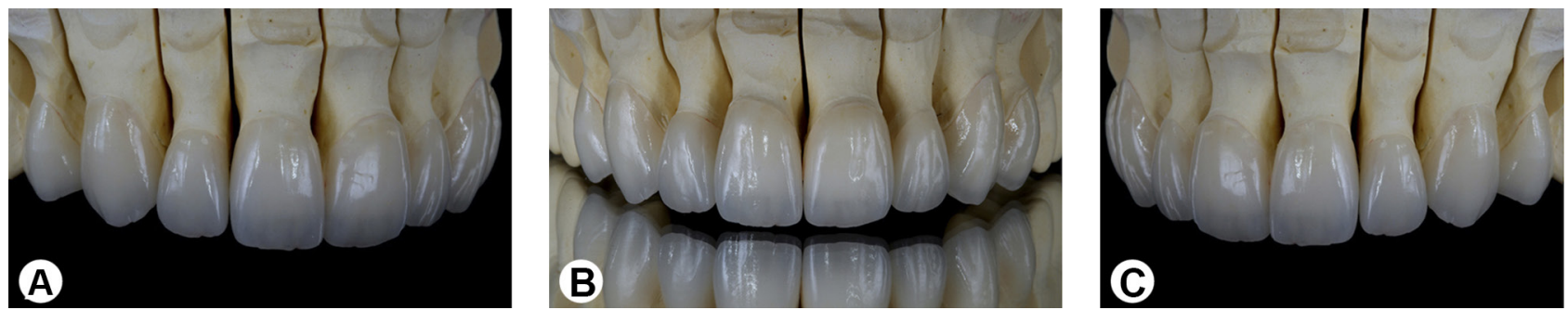

Figure 7. Feldspathic porcelain veneers finalized on the prepared cast (A-C). 
II; Ivoclar Vivadent). The restoration margins were light cured for $3 \mathrm{~s}$ on each side, excess material was removed and all restoration faces were light cured for $60 \mathrm{~s}$.

The maximum intercuspation occlusion was adjusted with diamond burs (\#3118F; KG Sorensen) in areas marked with articulating paper (AccuFilm II; Parkell Inc., Farmingdale, NY, USA), and the laterality and protrusion of mandibular movements was checked. The adjusted surfaces were polished using polishing rubber (Eve Diapol; Ernst Vetter $\mathrm{GmbH}$, Pforzheim, Germany) and the proximal surfaces were finished with finishing strips (Sof-Lex; 3M ESPE). The final appearance was evaluated immediately after cementation (Figs. 8 and 9) and after 36 months of clinical follow up (Fig. 10). None intercurrence was
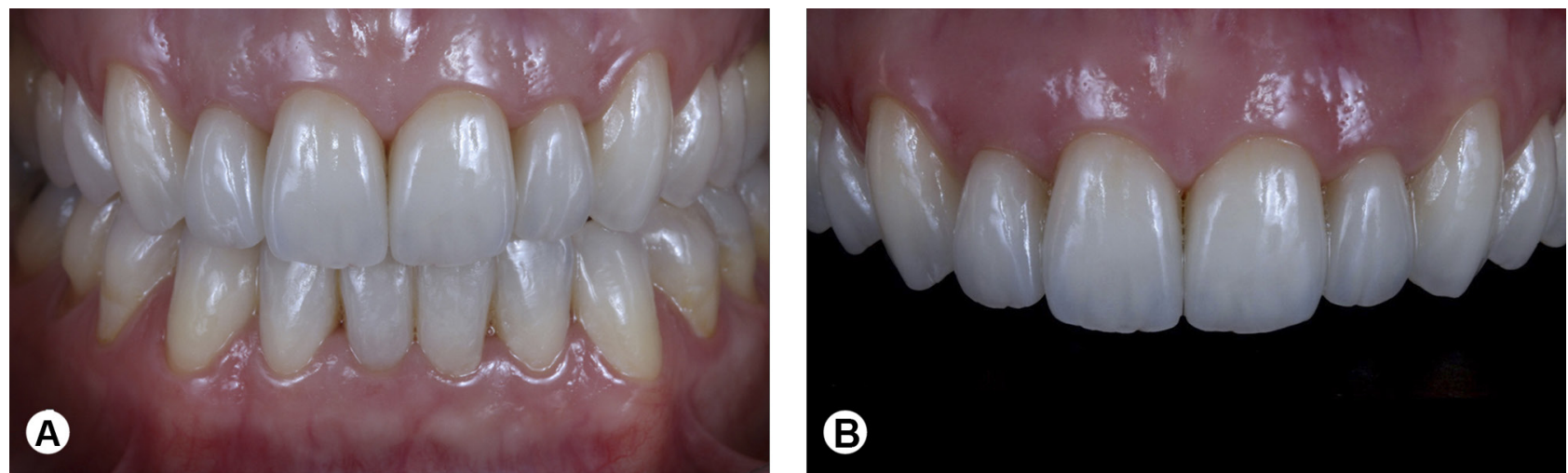

Figure 8. Intraoral views of the final appearance immediately after cementation: (A) maximum intercuspation and (B) maxillary anterior teeth.
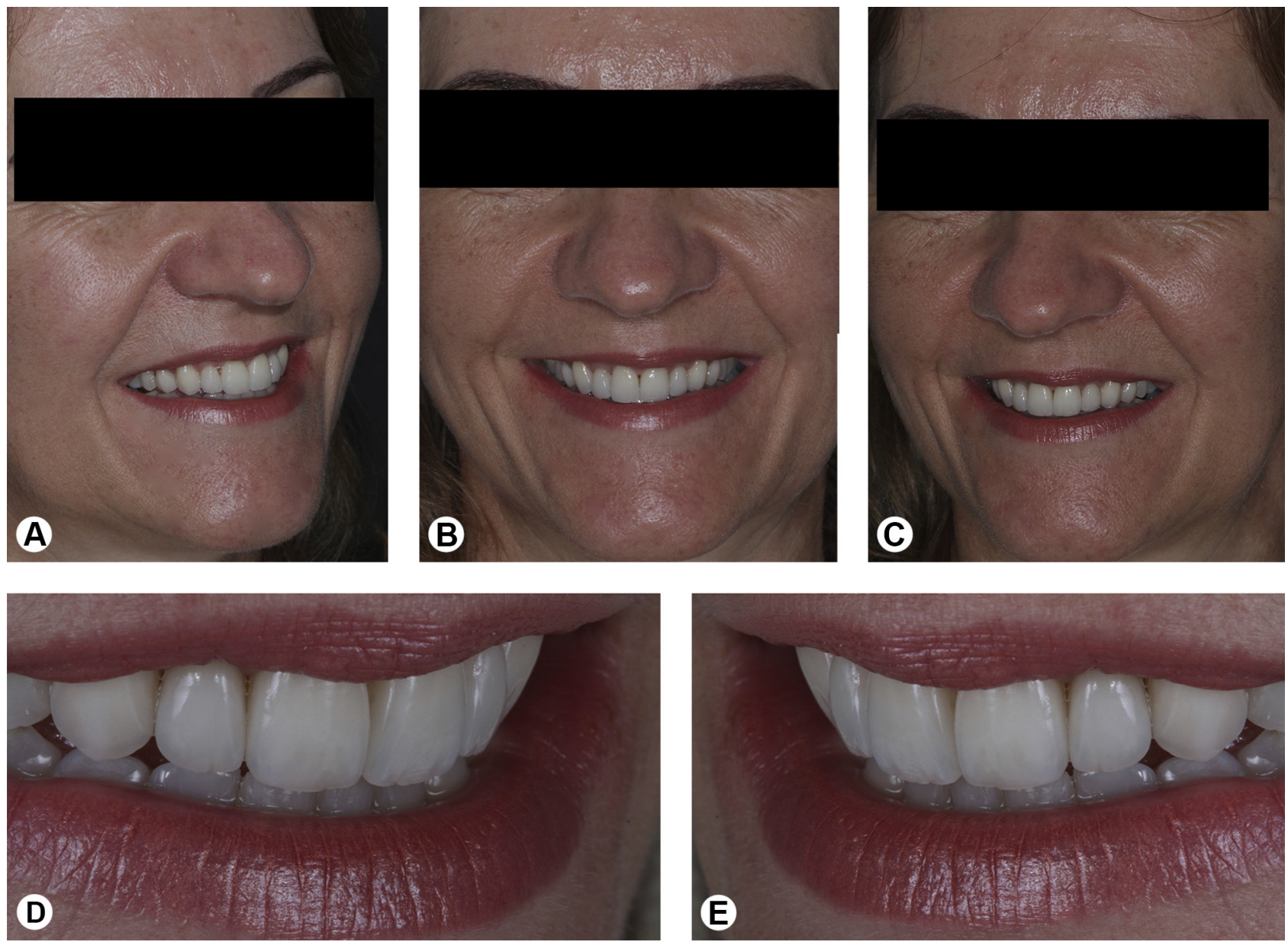

Figure 9. Final appearance of the smile. 
presented during the clinical follow up and the excellent results and patient satisfaction were achieved.

\section{Discussion}

Smile rehabilitation requires appropriate treatment planning and material selection, based on knowledge of the indications, contraindications, operatory technique and limitations of restorative materials. The treatment possibilities, including the use of composite resin restorations or porcelain laminate veneers, and associated advantages, disadvantages and limitations, were discussed with the patient. Tooth preparation using composite resin restorations is less invasive, but this material has limited longevity compared with ceramic restorations $(3,4)$. In addition, a recent systematic review of the longterm survival and reasons for failure of anterior resin composite restorations showed that unsatisfactory esthetic appearance (due to marginal staining and discoloration) was the main reason for restoration replacement (16). The use of ceramic restorations yields more esthetic long-term results due to their chemical composition and physical and biological properties (17).

The clinical success of ceramic restorations depends $\vec{s}$ of the selection of an appropriate ceramic material for each case. Three ceramic materials are currently available for laminate veneers: feldspathic porcelain, leucitereinforced ceramic and lithium disilicate-reinforced ceramic (7). The latter two ceramics have greater biaxial flexural strength $(125 \pm 14$ to $175 \pm 32 \mathrm{MPa}$ and $300 \pm 35$ to $440 \pm 45 \mathrm{MPa}$, respectively) (18-21). They are fabricated through a combination of lost-wax and heat-pressed techniques, or more recently using a CAD-CAM process (7). Clinically, these materials have an important advantage over feldspathic porcelain made on a refractory cast: they allow the correction of shape and/or color after proofing in the patient. However, manufacturing techniques make it difficult to obtain thin veneers with high esthetic value.
Feldspathic porcelain has a high degree of translucency and provides an excellent esthetic appearance; ceramists can use layering processes to make veneers from this material that optically approximate natural teeth (7). In the present case report, the laminate veneers were made with feldspathic porcelain due to these advantages. The technical limitations of this material include low flexural strength (about $63 \mathrm{MPa}$ ) prior to adhesive cementation (11); thus, ceramists and clinicians must be very careful during manufacture, esthetic proofing and restoration cementation. In addition, feldspathic porcelain veneer is manufactured using sculpting powder/liquid; therefore, the esthetic properties of such restorations depend on the ceramist's ability to build depth of anatomy, color, and translucency into the restoration. For this reason, communication between clinicians and ceramists is very important (22).

Patient requests for less-invasive treatments and greater esthetics have enhanced the indication for feldspathic porcelain veneers. This material enables the achievement of a thickness less than $0.5 \mathrm{~mm}$, with or without preparation in the enamel. A slight $0.3-$ to $0.5-\mathrm{mm}$ reduction of the tooth surface is important to preserve the health of the gingival tissues and prevent overcontouring (15). These conditions were achieved in this case, in which veneer thickness was approximately 0.3 to $0.5 \mathrm{~mm}$ in the cervical third, $0.7 \mathrm{~mm}$ in the middle third, and 1.5 to $2.0 \mathrm{~mm}$ in the incisal third, producing high esthetic value in this region. To control these parameters, the mock-up technique was applied prior to preparation, which enabled removal of the minimum amount of sound tooth tissue required for thin porcelain veneers (15). A diagnostic wax-up allows for final visualization of the irreversible procedure, which facilitates communication among the clinician, the patient and the dental laboratory technician $(23,24)$. Any required adjustment of the final tooth shape (e.g., incisal length and vestibular volume), or dental arrangement should
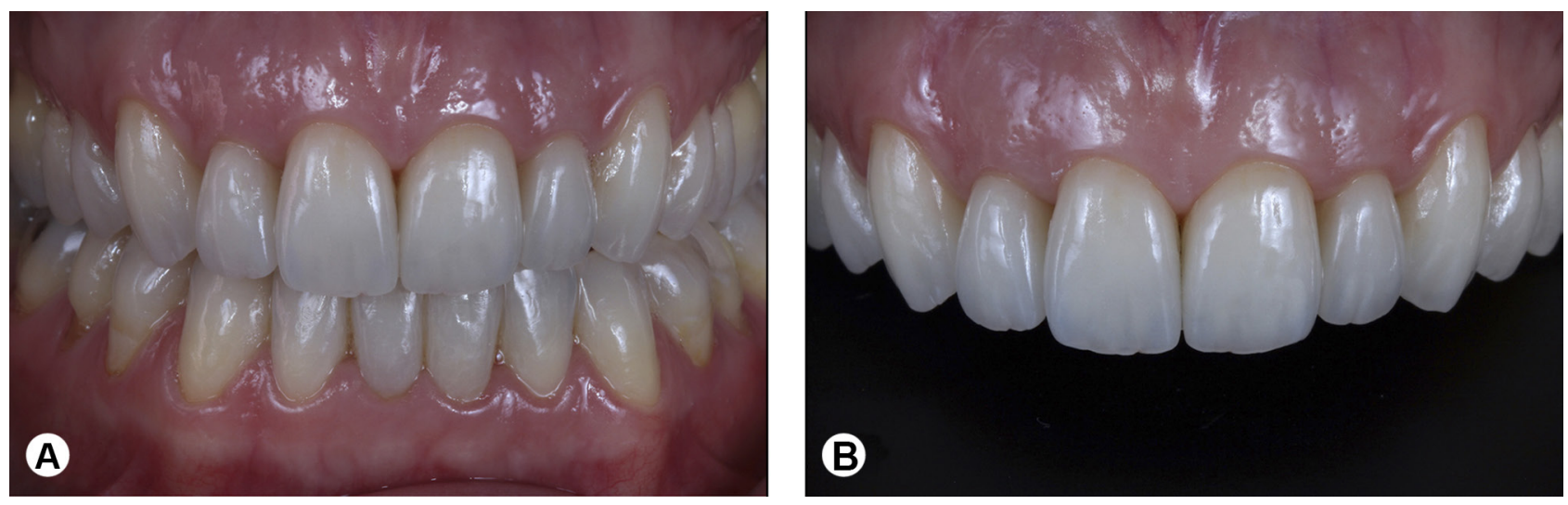

Figure 10. Intraoral views of the clinical follow-up evaluation after 36 months: (A) maximum intercuspation and (B) maxillary anterior teeth. 
be made on the wax-up prior to tooth preparation, and a new mock-up should be made and tested, since the feldspathic porcelain veneers does not allow for significant correction and the wax-up guides its manufacture. In addition, it aids the fabrication of provisional restorations, which are important to accommodate the gingival tissue to the restorative material and to preview the phonetics and occlusal comfort to be attained at the end of the treatment (15).

Several clinical studies have supported the use of feldspathic porcelain for laminate veneers; the survival rate of such restorations is more than $90 \%$ over 10 years of clinical service $(4,7)$. Layton and Walton (14) investigated the clinical outcome and estimated cumulative survival rate of feldspathic porcelain veneers $(n=499$, placed in 155 patients) over a 21-year follow-up period; they excluded teeth with less than $80 \%$ of enamel remaining after preparation. The results showed that feldspathic porcelain veneers have an excellent long-term survival rate (cumulative 21 -year survival, $96 \pm 2 \%$ ) and low failure rate when bonded to prepared enamel substrate. Overall, the literature provides reasonable evidence that porcelain veneers bonded to preparation in dentin adversely affects survival (17). Moreover, defects can be present at the margin of the veneer and an existing composite resin filling (4). These findings suggest that the success of feldspathic porcelain veneers depends on the bond with the dental substrate; proposed ideal conditions are that $50 \%$ or more of the bonded substrate is enamel and 70\% or more of the margin is enamel $(6,23)$. This issue was relevant to material selection in the current case, as the preparations were almost exclusively in enamel.

In the present case, light-cured resin cement was used, which interferes minimally with the esthetic stability of porcelain restorations. The original color of chemical- or dual-cured cement may change over time due to oxidation of the tertiary amine content, which can jeopardize the esthetic appearance of the restoration, especially in thin ceramic veneers (25). In addition to refractory technique, other limitation of feldspathic porcelain veneers is its high translucency. Feldspathic porcelain can be used to fabricate highly esthetic restorations and to reproduce characteristics that resemble the natural teeth. However, it certainly cannot be used to mask a darkened dental substrate.

Feldspathic porcelain veneers are indicated in cases requiring the alteration of tooth shape and slight change in color. This treatment presents advantages, such as minimal thickness of tooth reduction, bonding between porcelain and enamel, and a satisfactory esthetic result due to the inherent properties of the material. In the case presented here with a 3-year follow up, excellent clinical results and patient satisfaction were achieved.

\section{Resumo}

Este relato de caso descreve um tratamento estético para melhorar a forma e alinhamento dos dentes anteriores, restabelecendo a harmonia do sorriso por meio de laminados de porcelana feldspática. Resultados de acompanhamento clínico longitudinal de 36 meses também são apresentados. As vantagens, desvantagens e limitações da técnica são detalhadas com referência na literatura. Isto sugere que o sucesso do tratamento depende de adequadas condições de união entre o laminado e o complexo dental, o qual envolve parâmetros tais como resistência e durabilidade na interface de união. Assim, o sucesso clínico de laminados de porcelana feldspática depende de uma precisa seleção do caso e correta execução dos procedimentos clínicos e laboratoriais. A reabilitação envolveu de primeiro pré-molar direito a esquerdo com laminado de porcelana feldspática confeccionada em matriz refratária. Após 3 anos de acompanhamento, excelentes resultados clínicos e satisfação do paciente foram verificados.

\section{Acknowledgements}

The authors thank Eduardo Anacleto Gricolo (Calgaro Dental Laboratory, Curitiba, PR, Brazil), who made the porcelain laminate veneers.

\section{References}

1. Pinto RC, Chambrone $L$, Colombini $B L$, Ishikiriama SK, Britto IM, Romito GA. Minimally invasive esthetic therapy: a case report describing the advantages of a multidisciplinary approach. Quintessence Int 2013;44:385-391.

2. Ali Z, Eliyas $S$, Vere JW. Choosing the right dental material and making sense of the options: evidence and clinical recommendations. Eur J Prosthodont Restor Dent 2015;23:P150-P162.

3. Korkut B, Yanikoglu F, Gunday M. Direct composite laminate veneers: three case reports. J Dent Res Dent Clin Dent Prospects 2013;7:105-111.

4. Peumans M, De Munck J, Fieuws S, Lambrechts P, Vanherle G, Van Meerbeek B. A prospective ten-year clinical trial of porcelain veneers. J Adhes Dent 2004;6:65-76.

5. Belser UC, Magne P, Magne M. Ceramic laminate veneers: continuous evolution of indications. J Esthet Dent 1997;9:197-207.

6. Radz GM. Minimum thickness anterior porcelain restorations. Dent Clin North Am 2011;55:353-370.

7. Pini NP, Aguiar FH, Lima DA, Lovadino JR, Terada RS, Pascotto RC. Advances in dental veneers: materials, applications, and techniques. Clin Cosmet Investig Dent 2012;10:9-16.

8. Fleming GJ, Maguire FR, Bhamra G, Burke FM, Marquis PM. The strengthening mechanism of resin cements on porcelain surfaces. J Dent Res 2006;85:272-276.

9. Addison 0, Marquis PM, Fleming GJ. Adhesive luting of all-ceramic restorations--the impact of cementation variables and short-term water storage on the strength of a feldspathic dental ceramic. J Adhes Dent 2008;10:285-293.

10. Soares LD, Basso GR, Spazzin AO, Griggs J, Moraes RR. Mechanical reliability of air-abraded and acid-etched bonded feldspar ceramic. Dent Mater 2016;32:433-441.

11. Spazzin AO, Guarda GB, Oliveira-Ogliari A, Leal FB, Correr-Sobrinho L, Moraes RR. Strengthening of porcelain provided by resin cements and flowable composites. Oper Dent 2016;41:179-188.

12. Jha R, Jain V, Das TK, Shah N, Pruthi G. Comparison of marginal fidelity and surface roughness of porcelain veneers fabricated by refractory die and pressing techniques. J Prosthodont 2013;22:439-444.

13. da Cunha LF, Gonzaga CC, Saab R, Mushashe AM, Correr GM. Rehabilitation of the dominance of maxillary central incisors with refractory porcelain veneers requiring minimal tooth preparation. Quintessence Int 2015;46:837-841.

14. Layton DM, Walton TR. The up to 21-year clinical outcome and survival of feldspathic porcelain veneers: accounting for clustering. Int J Prosthodont 2007;25:604-612.

15. Magne $P$, Belser UC. Novel porcelain laminate preparation approach 
driven by a diagnostic mock-up. J al.Esthet Restor Dent 2004;16:7-16 ; discussion 17-8.

16. Demarco FF, Collares K, Coelho-de-Souza FH, Correa MB, Cenci MS, Moraes RR, et al.. Anterior composite restorations: A systematic review on long-term survival and reasons for failure. Dent Mater 2015;31:1214-1224.

17. Fradeani $M$, Redemagni $M$, Corrado M. Porcelain laminate veneers: 6 - to 12-year clinical evaluation--a retrospective study. Int J Periodontics Restorative Dent 2005;25:9-17.

18. Aurelio IL, Fraga S, Dorneles LS, Bottino MA, May LG. Extended glaze firing improves flexural strength of a glass ceramic. Dent Mater 2015;31:e316-e324.

19. Lien W, Roberts HW, Platt JA, Vandewalle KS, Hill TJ, Chu TM. Microstructural evolution and physical behavior of a lithium disilicate glass-ceramic. Dent Mater 2015;31:928-940.

20. Homaei E, Farhangdoost K, Tsoi JK, Matinlinna JP, Pow EH. Static and fatigue mechanical behavior of three dental CAD/CAM ceramics. J Mech Behav Biomed Mater 2016;59:304-313.

21. Stawarczyk B, Liebermann A, Eichberger M, Guth JF. Evaluation of mechanical and optical behavior of current esthetic dental restorative CAD/CAM composites. J Mech Behav Biomed Mater 2015;55:1-11.

22. McLaren EA, LeSage B. Feldspathic veneers: what are their indications? Compend Contin Educ Dent 2011;32:44-49.

23. Rotoli BT, Lima DA, Pini NP, Aguiar FH, Pereira GD, Paulillo LA. Porcelain veneers as an alternative for esthetic treatment: clinical report. Oper Dent 2013;38:459-466.

24. Reshad M, Cascione D, Magne P. Diagnostic mock-ups as an objective tool for predictable outcomes with porcelain laminate veneers in esthetically demanding patients: a clinical report. J Prosthet Dent 2008;99:333-339.

25. Almeida JR, Schmitt GU, Kaizer MR, Boscato N, Moraes RR. Resin-based luting agents and color stability of bonded ceramic veneers. J Prosthet Dent 2015;114:272-277.

Received July, 3, 2016 Accepted September 25, 2016 